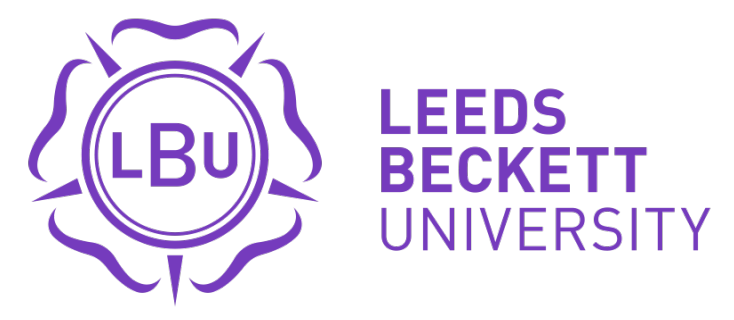

Citation:

Till, K and Cobley, S and O'Hara, J and Cooke, CB and Chapman, C (2013) Considering maturation status and relative age in the longitudinal evaluation of junior rugby league players. Scandinavian journal of medicine \& science in sports, 24 (3). 569 - 576 . ISSN 0905-7188 DOI: https://doi.org/10.1111/sms.12033

Link to Leeds Beckett Repository record:

https://eprints.leedsbeckett.ac.uk/id/eprint/199/

Document Version:

Article (Accepted Version)

The aim of the Leeds Beckett Repository is to provide open access to our research, as required by funder policies and permitted by publishers and copyright law.

The Leeds Beckett repository holds a wide range of publications, each of which has been checked for copyright and the relevant embargo period has been applied by the Research Services team.

We operate on a standard take-down policy. If you are the author or publisher of an output and you would like it removed from the repository, please contact us and we will investigate on a case-by-case basis.

Each thesis in the repository has been cleared where necessary by the author for third party copyright. If you would like a thesis to be removed from the repository or believe there is an issue with copyright, please contact us on openaccess@leedsbeckett.ac.uk and we will investigate on a case-by-case basis. 


\section{Considering maturation status and relative age in the longitudinal evaluation of junior}

rugby league players

Running head: Longitudinal evaluations in junior rugby

Kevin Till ${ }^{1}$, Steve Cobley ${ }^{2}$, John O'Hara ${ }^{1}$, Carlton Cooke ${ }^{1}$ and Chris Chapman ${ }^{3}$

${ }^{1}$ Carnegie Research Institute, Leeds Metropolitan University, Leeds, West Yorkshire, United Kingdom

${ }^{2}$ Faculty of Health Sciences, The University of Sydney, New South Wales, Australia ${ }^{3}$ Rugby Football League, Red Hall, Leeds, United Kingdom

Corresponding Author:

Dr. Kevin Till

Room 103, Fairfax Hall

Carnegie Faculty of Sport \& Education,

Headingley Campus, Leeds Metropolitan University

W.Yorkshire, LS6 3QS

Phone: (044-11) 01132-832600 Ext: 25185

Email: k.till@leedsmet.ac.uk 


\begin{abstract}
This study longitudinally evaluated whether maturation and relative age interact with time during adolescence to differentially affect the development of anthropometric and fitness characteristics in junior rugby league players. Anthropometric and fitness characteristics of 81 junior players selected into the UK Rugby Football League's talent identification and development process were assessed over three consecutive occasions (i.e., Under $13 \mathrm{~s}, 14 \mathrm{~s}, 15 \mathrm{~s})$. Players were grouped and compared in relation to maturational status (i.e., Early, Average, Late) and relative age quartile (i.e., Quartile 1). Repeated measures MANOVA identified significant $(p<0.001)$ overall main effects for maturation group, relative age quartile and importantly a maturation group by time interaction. Findings showed that the Early maturing group had the greatest anthropometric characteristics and medicine ball throw across the three occasions. However, the Late maturing group increased their height (Early $=$ 5.0, Late $=10.3 \mathrm{~cm})$, medicine ball throw and $60 \mathrm{~m}$ sprint $($ Early $=-0.46$, Late $=-0.85 \mathrm{~s})$ the most throughout the 2 year period. Early (de)selection policies currently applied in talent identification and development programmes are questionable when performance related variables are tracked longitudinally. During adolescence, maturation status alongside relative age should be considered and controlled for when assessing athlete potential for future progression.
\end{abstract}

Key Words: Talent Identification; Talent Development; Fitness; Anthropometry; Adolescence 


\section{Introduction}

The emphasis on the identification and development of 'talented' youth athletes is perceived to be crucial in the pursuit of sporting excellence (Williams \& Reilly, 2000), yet the ability to differentiate between an athlete's current adolescent performance and their potential for future progression, is complex (Reilly et al., 2000). Traditionally, studies within youth sport (e.g., volleyball, Gabbett et al., 2007; soccer, Gil et al., 2007; handball, Mohamed et al., 2009) have extrapolated the characteristics that contribute to expert adult performance and assessed them in junior samples using cross-sectional methodologies. Yet research based discussions (Vaeyens et al., 2008) emphasise how selection and cross-sectional assessments at 'one-off' time points within annual-age categories may be inaccurate in identifying longterm talent as adolescents who possess enhanced characteristics may not necessarily retain or translate these characteristics into exceptional adulthood performance (Abbott \& Collins, 2002; Howe et al., 1998). Therefore, longitudinal research designs measuring progression instead of 'one-off' performance are necessary if the talent development process is to be optimised, however such approaches within existing research are currently limited (EleferinkGemser et al., 2007; Falk et al., 2004).

The effects of maturation and/or training are possible explanations why adolescent characteristics may not translate into adult performance (Malina, et al., 2004a). For instance, anthropometric and fitness characteristics are influenced by the rate of growth and maturation (Philippaerts et al., 2006) and individuals can be (dis)advantaged on performance tasks when compared within chronological annual-age categories (Armstrong et al., 1998). Similarly, later maturing boys are usually outperformed by their earlier maturing peers (Malina, et al, 2004a), which has been demonstrated to lead to the over representative selection of relatively older (Cobley et al., 2009) and early maturing (Malina et al., 2004b; Sherar et al., 2007) players within competitive youth sport contexts. In the long term, this process may actually 
be counterproductive, as it may exclude equally skilled individuals from developmental opportunities due to their delayed physical characteristics when compared to their agematched counterparts.

To date, studies have examined the relationship between maturation (Figueiredo et al., 2009a; Till et al., 2010a) and relative age (Carling et al., 2009; Hirose, 2009; Malina et al., 2007) with performance characteristics using cross-sectional methodologies. Findings have demonstrated that maturation (e.g., intermittent endurance run - Late $=3070 \pm 643$, On time $=2478 \pm 935$, Early $=2617 \pm 902 \mathrm{~m}$; Figueiredo et al., 2009a) and relative age (e.g., Vertical jump - Quartile $(\mathrm{Q}) 1=43.1 \pm 6.0, \mathrm{Q} 2=42.0 \pm 4.5, \mathrm{Q} 3=44.1 \pm 6.9, \mathrm{Q} 4=41.9 \pm 5.9 \mathrm{~cm}$; Carling et al., 2009) were not related to fitness characteristics within a relatively homogenous high performance sample of junior soccer players. Whilst, previous longitudinal research (Lefevre et al., 1990) suggests that later maturing boys catch up in performance between adolescence and 30 years of age (e.g., Vertical Jump - Early $=-0.72 \mathrm{~cm}$, Average $=0.25 \mathrm{~cm}$, Later $=6.79 \mathrm{~cm})$, research tracking maturation, relative age, anthropometric and fitness characteristics longitudinally through adolescence has not occurred.

Between 2001 and 2008, the UK Rugby Football League (RFL) used a talent identification and development model, called the Player Performance Pathway (see Till et al., 2010b; 2011a for more details). Talented junior rugby league players (aged 13-15 years) were selected to the Player Performance Pathway on three consecutive occasions. Therefore, the purpose of the present study was to longitudinally evaluate the impact of maturation status, relative age and time (and their interactions) on the development of anthropometric and fitness characteristics in junior rugby league players.

\section{Materials and Methods}

\section{Participants}


Each year, 100 players were selected to the Regional representative level of the Player Performance Pathway at the Under 13s, 14s and 15s annual-age categories. Anthropometric and fitness testing was conducted on all players selected to the Pathway between 2005 and 2008 resulting in a total of 1,172 assessments. Within this sample, longitudinal data became available for players that were selected and retained to the Player Performance Pathway on three consecutive occasions (e.g., Under 13s in 2006, Under 14s in 2007 \& Under 15s in 2008). This resulted in 81 male junior rugby league players (mean age $13.62 \pm 0.24$ years at Under 13s) participating in the current study. The 81 players represented $41.3 \%$ (81 out of 196) of players who were retained in the Player Performance Pathway after initial selection at the Under 13s age category across the two cohorts examined (i.e., Under 13s 2005 - Under 15s 2007; Under 13s 2006 - Under 15s 2008). All protocols received institutional ethics approval with parental and/or guardian consent provided.

\section{Procedures}

Longitudinal data was examined respective of annual-age category (Under 13s, 14s \& 15s) according to devised 'maturation status' and 'relative age' groups. Maturation status was classified into 3 groups according to each player's Years from peak height velocity (YPHV) value at the Under 13s age category. Players were classified as either Late (YPHV below 0.33 years, $n=22$ ), Average (YPHV between -0.32 and 0.66 years, $n=39$ ) or Early (YPHV above 0.67 years, $n=20$ ) maturers. These groups were developed by subtracting or adding 0.50 years from the average YPHV $(0.17 \pm 0.59$ years $)$ at the Under $13 \mathrm{~s}$ age category, which resulted in at least a 1 year difference in maturation between the Late and Early maturing groups. Players remained in these maturational groups for analysis across all annual-age categories.

For relative age, player birth-dates were recoded to reflect their birth quartile (Q), according to the dates used for creating annual-age groups. September $1^{\text {st }}$ was used as the 
calendar start date for all annual-age categories within junior rugby league and therefore, players were categorised into quartiles (Q) accordingly (Cobley et al., 2009; Sherar et al., 2007), Quartile $1(\mathrm{Q} 1 ; n=44)=$ birth-dates between September and November; Q2 $(n=22)=$ December-February; Q3 ( $n=9)$ = March-May; and Q4 ( $n=6)$ = June-August, respectively.

\section{Measures}

All players selected to the Player Performance Pathway undertook a battery of anthropometric and fitness assessments at each of the three consecutive years. Leeds Metropolitan University Sport Science Support Team administered the testing protocol with assessments undertaken at the same time of day (i.e., early evening) and year (i.e., July) on each occasion. The assessment protocol used is detailed below with intraclass correlation coefficients for each measure presented in previous research (Till et al., 2010a; 2011b), which represent measurement reliability and objectivity to published expectations.

\section{Anthropometry}

Height and sitting height were measured using a Seca Alpha stand to the nearest $0.1 \mathrm{~cm}$. Body mass, wearing only shorts, was measured using calibrated Seca alpha (model 770) scales to the nearest $0.1 \mathrm{~kg}$. Sum of four skinfolds were determined by using calibrated Harpenden skinfold calipers (British Indicators, UK) to measure four skinfold sites (biceps, triceps, subscapular, suprailiac) in accordance with the guidelines by Hawes and Martin (2001).

\section{Maturation (Age at PHV)}

Maturation was assessed using an age at PHV prediction equation (Mirwald et al., 2002). This method used a gender-specific multiple regression equation including stature, sitting height, leg length, body mass, chronological age and their interactions to estimate age at PHV (Sherar et al., 2007). The 95\% confidence interval associated with this equation for 
boys is \pm 1.18 years (Mirwald et al., 2002) with YPHV calculated by subtracting age at PHV from chronological age.

\section{Fitness Characteristics}

To determine lower and upper body power, speed, change of direction speed and maximal aerobic power (estimated $\dot{V}_{2 \max }$ ) a number of fitness tests were conducted. Prior to testing a standardised warm up was performed and all players received full instructions. For each assessment the highest score of three attempts was used.

To assess lower body power, a countermovement jump with hands positioned on hips was used with jump height measured to the nearest $\mathrm{cm}$ (Hunter \& Marshall, 2002). To assess upper body power a 2kg medicine ball (Max Grip, China) chest throw (MBT) was used. Participants were instructed to throw the ball horizontally as far as possible while seated, with legs extended out in front of the body, with their back against a wall with distance measured to the nearest $0.1 \mathrm{~m}$ from the wall to where the ball landed (Stockbrugger \& Haennel, 2003). Running speed was assessed over 10m, 20m, 30m and 60m using timing gates (Brower Timing Systems, IR Emit, USA). Participants were positioned from a standing start $0.5 \mathrm{~m}$ behind the initial timing gate and were instructed to start in their own time with times recorded to the nearest $0.01 \mathrm{~s}$. Change of direction speed was assessed using the agility 505 test for left and right feet (Gabbett \& Herzig, 2004). Participants were positioned 15m from a turning point with timing gates positioned $10 \mathrm{~m}$ from the start point. Players accelerated from the starting point, through the timing gates, turned on the $15 \mathrm{~m}$ line and ran as quickly as possible back through the gates with times recorded to the nearest $0.01 \mathrm{~s}$. Maximal oxygen uptake was estimated using the multistage fitness test (Ramsbottom et al., 1988). Participants were required to shuttle run $20 \mathrm{~m}$, keeping to a series of beeps. Players running speed increased progressively until volitional exhaustion was reached. Regression equations were 
used to estimate $\dot{V} \mathrm{O}_{2 \max }$ from the level reached during the multistage fitness test (Ramsbottom et al., 1988).

\section{Statistical Analysis}

Mean and standard deviation (SD) scores were calculated for all dependant variables (i.e., anthropometric and fitness characteristics) at each annual-age category (i.e., Under 13s, $14 \mathrm{~s} \& 15 \mathrm{~s})$ according to maturation group and relative age quartile. To examine significant differences and interactions over time between independent variables, repeated measures MANOVA analyses were conducted. Following multivariate analysis, Bonferroni pairwise comparisons were conducted to examine univariate effects between each dependant variable. All analyses were conducted using SPSS 17.0 with effect sizes $\left(\eta^{2}\right)$ calculated and significance levels set at $p<0.05$.

\section{Results}

\section{Maturation Group}

Table 1 shows the anthropometric and fitness characteristics of all longitudinal players at each annual-age category (Under $13 \mathrm{~s}, 14 \mathrm{~s} \& 15 \mathrm{~s}$ ) according to maturation group (i.e., Late, Average, Early). MANOVA analyses identified a significant overall main effect for maturation group $\left(\mathrm{F}_{30,128}=6.328, p<0.001, \eta^{2}=0.597\right)$ with significant differences found between maturational groups for chronological age $\left(\mathrm{F}_{2,80}=8.38, p=0.001, \eta^{2}=0.177\right)$, height $\left(\mathrm{F}_{2,80}=38.76, p<0.001, \eta^{2}=0.498\right)$, sitting height $\left(\mathrm{F}_{2,80}=74.88, p<0.001, \eta^{2}=0.658\right)$, body mass $\left(\mathrm{F}_{2,80}=24.68, p<0.001, \eta^{2}=0.388\right)$ and medicine ball throw $\left(\mathrm{F}_{2,80}=14.61\right.$, $p<0.001, \eta^{2}=0.273$ ). Pairwise comparisons demonstrated that the Early maturing group had the significantly greater scores on each of these measures across the three testing occasions.

$$
\text { ***Insert Table } 1 \text { here*** }
$$


Significant overall main effects were found for maturation group $\mathrm{x}$ time interaction $\left(\mathrm{F}_{60,98}=2.101, p=0.01, \eta^{2}=0.563\right)$ with significant univariate effects found for height $\left(\mathrm{F}_{6,80}\right.$ $\left.=13.04, p<0.001, \eta^{2}=0.251\right)$, sitting height $\left(\mathrm{F}_{6,80}=18.59, p<0.001, \eta^{2}=0.323\right)$, sum of four skinfolds $\left(\mathrm{F}_{6,80}=2.53, p=0.043, \eta^{2}=0.061\right)$, medicine ball throw $\left(\mathrm{F}_{6,80}=2.62, p=0.037, \eta^{2}\right.$ $=0.063)$ and $60 \mathrm{~m}$ sprint $\left(\mathrm{F}_{6,80}=2.63, p=0.04, \eta^{2}=0.063\right)$. For all of these particular variables, significant effects identified that the Late maturing group improved to a greater extent when compared to the Average and Early maturers. Figures 1, 2 and 3 illustrate the changes in height, medicine ball throw and 60m sprint respectively between the Under $13 \mathrm{~s}$ and $15 \mathrm{~s}$ age categories.

$$
\text { ***Insert Figures 1, } 2 \text { and } 3 \text { here*** }
$$

\section{Relative Age}

Table 2 shows the anthropometric and fitness characteristics at each annual-age category (Under 13s, 14s \& 15s) according to relative age quartile (i.e., Q1, Q2, Q3, Q4). MANOVA analyses identified significant overall main effects for relative age $\left(\mathrm{F}_{45,188}=\right.$ $\left.6.614, p<0.001, \eta^{2}=0.609\right)$ with significant differences found for chronological age $\left(\mathrm{F}_{3,80}=\right.$ 190.79, $\left.p<0.001, \eta^{2}=0.881\right)$ and sitting height $\left(\mathrm{F}_{3,80}=2.91, p=0.040, \eta^{2}=0.102\right)$. Pairwise comparisons demonstrated that Q1 players were the oldest and Q3 had a greater sitting height than Q4 players.

No significant overall main effect was found for the relative age $\mathrm{x}$ time interaction $\left(\mathrm{F}_{90,145}=0.971, p=0.558, \eta^{2}=0.376\right)$. However, significant univariate interaction effects were found for height $\left(\mathrm{F}_{6,80}=4.73, p=0.001, \eta^{2}=0.156\right)$, sitting height $\left(\mathrm{F}_{6,80}=5.13\right.$, $\left.p<0.001, \eta^{2}=0.167\right)$ and estimated $\dot{V} \mathrm{O}_{2 \max }\left(\mathrm{F}_{6,80}=2.48, p=0.028, \eta^{2}=0.088\right)$. Height (Figure 4) increased the most in Q4 players across the two years with the lowest increase found in Q1 players. Q3 players improved estimated $\dot{V} \mathrm{O}_{2 \max }$ (Figure 5) the most across the two years followed by Q2, Q4 and Q1. 
*** Insert Table 2 and Figures 4 and 5 here***

\section{Discussion}

Due to the specific limitations within youth sport talent identification research and practice, the purpose of this study was to longitudinally evaluate the impact of maturation status, relative age and time (and their interactions) on the development of anthropometric and fitness characteristics in junior rugby league players. Findings demonstrated significant general main effects for maturation status with the earlier maturing players demonstrating greater anthropometric characteristics and upper body power (i.e., med ball throw) than the average and later maturing players. When changes in anthropometric and fitness characteristics were measured by maturation group over time, significant interactions were apparent with the Later maturing group increasing height, upper body power and $60 \mathrm{~m}$ sprint more than the Early maturing players.

\section{Maturation}

During adolescence, physical performance is correlated with biological maturation (Philippaerts et al., 2006) with previous research showing a gradient of performance in adolescent males for early $>$ average $>$ later maturers in strength, speed, power and agility (Lefevre et al., 1990). The current analysis found overall main effects for maturation group with significant differences identified for chronological age and anthropometric variables (i.e., height, sitting height, body mass). As expected for each variable, the early maturing players had the greatest values, which support relationships previously found between chronological age, maturation and body size (Malina, 1994; Malina et al., 2004a; Sherar et al., 2007). For fitness characteristics, no significant differences were identified for any characteristic except medicine ball chest throw, which supports previous covariate findings (Till et al., 2011b) that maturation is strongly related to upper body power. Further, the 
current findings demonstrate that within a high performing representative group of junior rugby league players that later maturing selected players were not significantly outperformed by earlier maturing players on a range of fitness tests across a two year period. These findings are similar to prior cross-sectional results within junior rugby league (Till et al., 2010a) and youth soccer, whereby no differences were identified between later, average and earlier maturing $11-14$ year old boys for functional capacities (Figueiredo et al., 2009b). These findings suggest that within representative youth sport squads an advanced maturation status does not necessarily translate to greater fitness performance. Previous research (Till et al., 2010a) has demonstrated that aspects of body composition (i.e., body fat) may constrain fitness performance within earlier maturing junior rugby league players (Till et al., 2010a). A maturation group by time interaction was evident for anthropometric (i.e., height, sitting height) and fitness (i.e., medicine ball throw, $60 \mathrm{~m}$ sprint) characteristics. Changes in height $($ Late $=10.3$, Average $=6.9$, Early $=5.0 \mathrm{~cm})$ and sitting height $($ Late $=6.7$, Average $=$ 4.4, Early $=3.2 \mathrm{~cm}$ ) were greater in the Late maturing players across the two year period demonstrating that later maturers have a greater potential for growth. For physical performance, medicine ball chest throw $($ Late $=1.4$, Average $=1.1$, Early $=1.0 \mathrm{~m})$ and $60 \mathrm{~m}$ sprint $($ Late $=-0.85$, Average $=-0.65$, Early $=-0.46 \mathrm{~s})$ produced significantly greater improvements in the Late maturing group between the Under 13 and 15 annual-age categories. Changes in upper body power and sprint speed are therefore related to maturation, as demonstrated in previous research (Mendez-Villanueva, et al., 2011) which could be explained by a number of physiological factors such as rise in circulating concentrations of testosterone and growth hormone, enhancement of neural function and multi joint coordination (Malina et al., 2004a).

Although the current study is limited by its categorisation of maturational groups (i.e., \pm 0.5 years from the mean YPHV) compared to previous research using \pm 1.0 years (Baxter- 
Jones et al., 2003; Matthys et al., 2012), the findings identify that there is a greater potential for later maturing players to 'catch-up' and possibly overtake earlier maturing players on fitness variables during adolescence (Lefevre et al., 1990; Le Gall et al., 2002). This finding questions the early (de)selection policies currently used in talent identification and development programmes, whereby later maturing players have limited selection opportunities into representative and developmental squads. This early (de)selection policy is supported by previous research findings (Le Gall et al., 2010), which identified that youth academy (Under 14-16) soccer players who turned professional were more likely to be later maturing than players who ended up as amateur players. Therefore, it is essential that player progression, alongside maturation, should be monitored over time to aid the long-term development of athletes in youth sport contexts (Vaeyens et al., 2008).

\section{Relative Age}

Previous cross-sectional studies (Carling et al., 2009; Hirose, 2009; Malina et al., 2004b) have compared anthropometric and fitness characteristics with relative age, but no study has analysed these differences within a longitudinal sample. Current findings demonstrated an overall effect for relative age with significant differences between quartiles apparent for chronological age and sitting height. The effect of relative age on other anthropometric and the fitness characteristics in this particular sample were negligible, consistent with previous indications in rugby league (Till et al., 2010a) and youth soccer (Carling et al., 2009; Hirose, 2009; Malina et al., 2004b). This suggests that the players consistently selected to the Player Performance Pathway were physically homogenous regardless of relative age and that being born later in the year does not necessarily mean a player is physically disadvantaged (Carling et al., 2009), even though the odds of being physical disadvantaged are higher. 
An overall significant effect for the interaction between relative age and time was not apparent. However, significant interactions occurred for height, sitting height and estimated $\dot{V} \mathrm{O}_{2 \max }$. The greatest increases in height $(\mathrm{Q} 1=6.13, \mathrm{Q} 2=8.43, \mathrm{Q} 3=8.01, \mathrm{Q} 4=11.95 \mathrm{~cm})$ were found in Q4 players, which could be explained by them being more likely to be still maturing $(\mathrm{Q} 4=-0.68 \mathrm{YPHV}$ at Under 13s) due to their lower chronological age. Although relatively younger players may be significantly shorter at younger ages (e.g., 13 years old) they will more than likely 'catch-up' with chronological age and maturation. The interactions amongst maturation and relative age with height suggest that talent identification and selection models should not select based on size, particularly coaches and scouts who have a 'he's too small, he won't make it' philosophy. Instead, talent identification and development programmes should regularly monitor height or use a predictive height equation (e.g., Sherar et al., 2005) for considering the selection of players in the long-term.

For estimated $\dot{V} \mathrm{O}_{2 \max }$, the greatest change in performance was found in the Q3 players $\left(\mathrm{Q} 1=2.0, \mathrm{Q} 2=4.6, \mathrm{Q} 3=6.9, \mathrm{Q} 4=3.8 \mathrm{ml} \cdot \mathrm{kg}^{-1} \cdot \mathrm{min}^{-1}\right)$, who were significantly the worst performing at the under $13 \mathrm{~s}$ age category $(\mathrm{Q} 1=48.7, \mathrm{Q} 2=47.6, \mathrm{Q} 3=43.7, \mathrm{Q} 4=50.2 \mathrm{ml} . \mathrm{kg}$ $\left.{ }^{1} \cdot \mathrm{min}^{-1}\right)$. This finding demonstrates the need to improve aerobic power to be consistently selected to the Player Performance Pathway and is irrespective of relative age. These findings demonstrate that after initial selection into a talent programme, relative age may not influence an athlete being retained or subsequently selected within a programme. For example, if a Quartile 4 individual was initially selected, it is likely that they required fitness or anthropometric characteristics similar to their relatively older counterpart (i.e., Q1). For most of the Q4 players selected in this sample, their fitness characteristics matched those of the relatively older players. That said, it remains that, the number of players not initially selected due to the influence of relative age and the likelihood of showing more advanced stages of maturations is a problem within sport-related identification and selection processes. 


\section{Perspectives}

The present study has demonstrated that maturation and relative age (alongside their interactions with time) affect the development of anthropometric and fitness characteristics during adolescence. Later maturing athletes appear to show more progression and 'catch-up' the early maturing player during adolescence over a two-year period. These development trajectories may continue into later adolescence and adulthood, questioning the validity of early (de)selection policies currently applied in youth sports talent identification, selection and development. The relatively younger and late maturing adolescent player, may exhibit an alternative developmental trajectory, which is undetectable using cross-sectional assessment, especially within chronological annual-age categories. However, due to current talent identification and selection systems emphasising an immediate short-term performance, the potential of these players may be hidden but may hold significant promise in longer-term attainment (senior adult performance). Therefore, one-off assessments and selection processes currently used within chronological annual-age groups in youth sport could repeatedly constrain (longer-term) individual sport participation and attainment. Instead, longitudinal assessments analysing the change in performance, considering both maturation status and relative age should be considered more appropriate. 


\section{References}

1. Abbott A, Collins D. A theoretical and empirical analysis of a 'state of the art' talent identification model. High Ability Studies 2002; 13: 157-178.

2. Armstrong N, Welsby JR, Kirby BJ. Peak oxygen uptake and maturation in 12 year olds. Med Sci Sport Exerc 1998; 30: 165-169.

3. Baxter-Jones ADG, Maffulli N, Mirwald RL. Does elite competition inhibit growth and delay maturation in some gymnasts? Probably not. Pediatr Exerc Sci 2003; 15: 373-382.

4. Carling C, le Gall F, Reilly T, William AM. Do anthropometric and fitness characteristics vary according to birth date distribution in elite youth academy soccer players. Scand J Med Sci Sport 2009; 19: 3-9.

5. Cobley S, Baker J, Wattie N, Mckenna, J. Annual age-grouping and athlete development: A meta-analytical review of relative age effects in sport. Sports Med 2009; 39: 235-256.

6. Elferink-Gemser MT, Visscher C, Lemmink KAPM, Mulder T. Multidimensional performance characteristics and standard of performance in talented youth field hockey players: A longitudinal study. J Sports Sci 2007; 25: 481-489.

7. Falk B, Lidor R, Lander YT, Lang B. Talent identification and early development of elite water polo players: a 2 year follow up. J Sports Sci 2004; 22: 347-355.

8. Figueiredo AJ, Goncalves CE, Silva MJCE, Malina RM. Youth soccer players 11-14 years: Maturity, size, function, skill and goal orientation. Ann Hum Biol 2009a; 36: 6073.

9. Figueiredo AJ, Goncalves CE, Silva MJCE, Malina RM. Characteristics of youth soccer players who drop out, persist or move up. J Sports Sci 2009b; 27: 883-891.

10. Gabbett TJ, Herzig PJ. Physiological characteristics of junior elite and sub-elite rugby league players. Strength Cond Coach 2004; 12: 19-24. 
11. Gabbett TJ, Georgieff B, Domrow N. The use of physiological, anthropometric and skill data to predict selection in a talent-identified junior volleyball squad. J Sports Sci 2007; 25: $1337-1344$.

12. Gil S, Ruiz F, Irazusta A, Gil J, Irazusta J. Selection of young soccer players in terms of anthropometric and physiological factors. J Sports Med Phys Fitness 2007; 47: 25-32.

13. Hawes MR, Martin AD. Human Body Composition. In: Eston R. ed. and Reilly T. ed. Kinanthropometry and exercise physiology laboratory manual: Tests, procedures and data second edition. Volume 1: Anthropometry. London, Routledge. 2001: 7-43.

14. Hirose N. Relationships among birth-month distributions, skeletal age and anthropometric characteristics in adolescent elite soccer players. J Sports Sci 2009: 27: $1159-1166$.

15. Howe M JA, Davidson JW, Sloboda JA. Innate talents: Reality of myth? Behavioural and Brain Sciences 1998; 21: 399-442.

16. Hunter JP, Marshall, RN. Effects of power and flexibility training on vertical jump technique. Med Sci Sport Exerc 2002; 34: 478-486.

17. Lefevre J, Beunen G, Steens G, Claessens A, Renson R. Motor performance during adolescence and age thirty as related to peak height velocity. Ann Hum Biol 1990; 17: 423-435.

18. Le Gall F, Beillot J, Rochcongar P. The improvement in maximal aerobic power of soccer players during growth. Science in Sports 2002; 17: 177-188.

19. Le Gall F, Carling C, Williams M, Reilly T. Anthropometric and fitness characteristics of international, professional and amateur male graduate soccer players from an elite youth academy. J Sci Med Sport 2010; 13: 90-95.

20. Malina RM. Physical Growth and Biological Maturation of Young Athletes. Exerc Sport Sci Rev 1994; 22: 389-433. 
21. Malina RM, Bouchard C, Bar-Or O. Growth, Maturation, and Physical Activity (2nd ed.). United States of America; Human Kinetics. 2004a.

22. Malina RM, Eisenmann JC, Cumming SP, Ribeiro B, Aroso J. Maturity-associated variation in the growth and functional capacities of youth football (soccer) players 13-15 years. Eur J Appl Physiol, 2004b; 91: 555-562.

23. Malina RM, Ribeiro B, Aroso J, Cumming SP. Characteristics of youth soccer players aged 13-15 classified by skill level. Br J Sports Med 2007; 41: 290-295.

24. Matthys SPJ, Vaeyens R, Coelho-e-Silva MJ, Lenoir M, Philippaerts R. The Contribution of Growth and Maturation in the Functional Capacity and Skill Performance of Male Adolescent Handball Players. Int J Sports Med 2012; 33: 543-549.

25. Mendez-Villanueva A, Buchheit M, Kuitunen S, Douglas A, Peltola E, Bourdon P. Agerelated differences in acceleration, maximum running speed, and repeated-sprint performance in young soccer players. J Sports Sci 2011; 29: 477-484.

26. Mirwald RL, Baxter-Jones ADG, Bailey DA, Beunen GP. An assessment of maturity from anthropometric measurements. Med Sci Sport Exerc 2002; 34: 689-694.

27. Mohamed H, Vaeyens R, Matthys S, Multael M, Lefevre J, Lenoir M, Philppaerts R. Anthropometric and performance measures for the development of a talent detection and identification model in youth handball. J Sports Sci 2009; 27: 257-266.

28. Philippaerts RM, Vaeyens R, Janssens M, Van Renterghem B, Matthys D, Craen R, Bourgois J, Vrijens J, Beunen G, Malina RM. The relationship between peak height velocity and physical performance in youth soccer players. J Sports Sci 2006; 24: 221230.

29. Ramsbottom R, Brewer J, Williams C. A progressive shuttle run test to estimate maximal oxygen uptake. Br J Sports Med 1988; 22: 141-144. 
30. Reilly T, Williams AM, Nevill A, Franks A. A multidisciplinary approach to talent identification in soccer. J Sports Sci 2000; 18: 695-702.

31. Sherar LB, Mirwald RL, Baxter-Jones ADG, Thomis M. Prediction of adult height using maturity based cumulative height velocity curves. J Pediatr 2005; 147: 508-514.

32. Sherar LB, Baxter-Jones ADG, Faulkner RA, Russell KW. Do physical maturity and birth date predict talent in male youth ice hockey players? J Sports Sci 2007; 25: 879886.

33. Stockbrugger BA, Haennel RG. Contributing factors to performance of a medicine ball explosive power test: a comparison between jump and non jump athletes. J Str Cond Res 2003; 17: 768-774.

34. Till K, Cobley S, O'Hara J, Chapman C, Cooke C. Anthropometric, physiological and selection characteristics in high performance UK junior Rugby League players. Talent Development and Excellence 2010a; 2: 193-207.

35. Till K, Cobley S, Wattie N, O’Hara J, Cooke C, Chapman C. The prevalence, influential factors and mechanisms of relative age effects in UK Rugby League. Scand J Med Sci Sports 2010b; 20: 320-329.

36. Till K, Chapman C, Cobley S, O'Hara J, Cooke C. Talent Identification, Selection and Development in UK Junior Rugby League: An Evolving Process. In: Talent Identification and Development in Sport: International Perspectives. 2011a: Routledge.

37. Till K, Cobley S, O'Hara J, Brightmore A, Cooke C, Chapman C. Using Anthropometric and Performance Characteristics to Predict Selection in Junior UK Rugby League Players. J Sci Med Sport 2011b; 14: 264-269.

38. Vaeyens R, Lenoir M, Williams AM, Philippaerts RM. Talent identification and development programmes in sport: Current models and future directions. Sports Med 2008; 38: 703-714. 
39. Williams AM, Reilly T. Talent identification and development in soccer. J Sports Sci 2000; 18: 657-667. 
Table 1: Anthropometric and Fitness Characteristics of Players as a Function of Maturation Group at U13s, 14s \& 15s.

\begin{tabular}{|c|c|c|c|c|c|c|c|c|c|c|}
\hline & \multicolumn{3}{|c|}{ Late (1) } & \multicolumn{3}{|c|}{ Average (2) } & \multicolumn{3}{|c|}{ Earlier (3) } & \multirow[b]{2}{*}{ Pairwise } \\
\hline & U13s & U14s & $\mathbf{U 1 5 s}$ & U13s & U14s & U15s & U13s & U14s & U15s & \\
\hline Age (years) & $13.47 \pm 0.29$ & $14.47 \pm 0.29$ & $15.47 \pm 0.29$ & $13.67 \pm 0.18$ & $14.67 \pm 0.18$ & $15.67 \pm 0.18$ & $13.71 \pm 0.18$ & $14.71 \pm 0.18$ & $15.71 \pm 0.18$ & $1<2,3$ \\
\hline Height (cm) & $163.4 \pm 4.3$ & $169.6 \pm 3.3$ & $173.7 \pm 3.2$ & $172.0 \pm 4.4$ & $176.4 \pm 4.9$ & $178.9 \pm 5.4$ & $178.1 \pm 5.1$ & $181.3 \pm 4.8$ & $183.1 \pm 4.5$ & $1<2<3$ \\
\hline Sitting Height (cm) & $81.3 \pm 2.9$ & $85.6 \pm 2.5$ & $88.0 \pm 2.7$ & $86.9 \pm 1.8$ & $89.7 \pm 1.9$ & $91.3 \pm 2.0$ & $90.9 \pm 2.1$ & $92.9 \pm 2.0$ & $94.1 \pm 2.1$ & $1<2<3$ \\
\hline Body Mass (kg) & $55.4 \pm 6.5$ & $63.4 \pm 7.2$ & $70.2 \pm 6.6$ & $63.7 \pm 7.9$ & $71.3 \pm 7.7$ & $77.1 \pm 8.0$ & $73.5 \pm 7.2$ & $79.7 \pm 8.3$ & $86.4 \pm 9.1$ & $1<2<3$ \\
\hline$\sum$ Skinfolds (mm) & $34.9 \pm 13.7$ & $37.2 \pm 15.4$ & $37.6 \pm 13.9$ & $33.6 \pm 12.0$ & $38.5 \pm 14.1$ & $42.4 \pm 14.6$ & $42.8 \pm 19.6$ & $43.5 \pm 16.3$ & $47.2 \pm 19.7$ & \\
\hline Vertical Jump (cm) & $37.4 \pm 4.6$ & $40.6 \pm 4.6$ & $43.6 \pm 5.1$ & $39.2 \pm 4.8$ & $41.6 \pm 4.6$ & $43.6 \pm 5.2$ & $40.0 \pm 5.7$ & $41.4 \pm 4.1$ & $43.0 \pm 5.2$ & \\
\hline Medicine Ball Throw (m) & $4.9 \pm 0.6$ & $5.7 \pm 0.5$ & $6.3 \pm 0.5$ & $5.4 \pm 0.4$ & $5.9 \pm 0.5$ & $6.5 \pm 0.6$ & $5.9 \pm 0.7$ & $6.3 \pm 0.4$ & $6.9 \pm 0.5$ & $1<2,3$ \\
\hline 10m Sprint (s) & $1.97 \pm 0.11$ & $1.90 \pm 0.09$ & $1.87 \pm 0.07$ & $1.95 \pm 0.07$ & $1.90 \pm 0.08$ & $1.85 \pm 0.07$ & $1.96 \pm 0.08$ & $1.93 \pm 0.09$ & $1.90 \pm 0.09$ & \\
\hline 20m Sprint (s) & $3.39 \pm 0.20$ & $3.27 \pm 0.17$ & $3.17 \pm 0.11$ & $3.35 \pm 0.14$ & $3.25 \pm 0.12$ & $3.17 \pm 0.12$ & $3.33 \pm 0.14$ & $3.26 \pm 0.14$ & $3.20 \pm 0.14$ & \\
\hline 30m Sprint (s) & $4.76 \pm 0.30$ & $4.55 \pm 0.24$ & $4.39 \pm 0.17$ & $4.68 \pm 0.21$ & $4.52 \pm 0.18$ & $4.40 \pm 0.19$ & $4.66 \pm 0.19$ & $4.54 \pm 0.19$ & $4.44 \pm 0.21$ & \\
\hline 60m Sprint (s) & $8.90 \pm 0.72$ & $8.44 \pm 0.52$ & $8.05 \pm 0.36$ & $8.76 \pm 0.47$ & $8.37 \pm 0.37$ & $8.09 \pm 0.44$ & $8.63 \pm 0.44$ & $8.35 \pm 0.39$ & $8.17 \pm 0.42$ & \\
\hline Agility 505 Left (s) & $2.60 \pm 0.13$ & $2.49 \pm 0.10$ & $2.42 \pm 0.10$ & $2.55 \pm 0.11$ & $2.44 \pm 0.10$ & $2.43 \pm 0.14$ & $2.56 \pm 0.17$ & $2.51 \pm 0.10$ & $2.46 \pm 0.15$ & \\
\hline Agility 505 Right (s) & $2.58 \pm 0.16$ & $2.48 \pm 0.10$ & $2.46 \pm 0.11$ & $2.57 \pm 0.13$ & $2.46 \pm 0.12$ & $2.44 \pm 0.16$ & $2.57 \pm 0.19$ & $2.53 \pm 0.12$ & $2.51 \pm 0.14$ & \\
\hline $\begin{array}{l}\text { Estimated } \dot{V} \mathrm{O}_{2 \max } \\
\left(\mathrm{ml} \cdot \mathrm{kg}^{-1} \cdot \mathrm{min}^{-1}\right)\end{array}$ & $48.8 \pm 4.0$ & $49.1 \pm 4.1$ & $51.2 \pm 3.4$ & $48.1 \pm 5.8$ & $51.0 \pm 4.7$ & $51.3 \pm 4.4$ & $46.5 \pm 5.5$ & $49.4 \pm 5.5$ & $51.2 \pm 5.9$ & \\
\hline
\end{tabular}

Note: The numbers in parentheses in column headings relate to the numbers used for illustrating significant (p<0.05) differences in the pairwise analysis; 
Table 2: Anthropometric and Fitness Characteristics of Players as a Function of Relative Age at U13s, 14s \& 15s.

\begin{tabular}{|c|c|c|c|c|c|c|c|}
\hline & \multicolumn{3}{|c|}{ Quartile 1 (1) } & \multicolumn{3}{|c|}{ Quartile 2 (2) } & \multirow[b]{2}{*}{ Pairwise } \\
\hline & U13s & $\mathrm{U} 14 \mathrm{~s}$ & $\mathrm{U} 15 \mathrm{~s}$ & $\mathrm{U} 13 \mathrm{~s}$ & U14s & U15s & \\
\hline Age (years) & $13.79 \pm 0.07$ & $14.79 \pm 0.07$ & $15.79 \pm 0.07$ & $13.58 \pm 0.08$ & $14.58 \pm 0.08$ & $15.58 \pm 0.08$ & $1>2>3>4$ \\
\hline Height $(\mathrm{cm})$ & $172.8 \pm 6.4$ & $176.8 \pm 6.1$ & $178.8 \pm 6.1$ & $169.5 \pm 6.9$ & $174.7 \pm 6.1$ & $177.7 \pm 5.5$ & \\
\hline Sitting Height $(\mathrm{cm})$ & $87.0 \pm 3.7$ & $89.7 \pm 3.3$ & $91.1 \pm 3.0$ & $85.7 \pm 3.6$ & $88.9 \pm 3.0$ & $90.8 \pm 2.5$ & $3>4$ \\
\hline Body Mass (kg) & $65.1 \pm 9.6$ & $71.8 \pm 9.2$ & $78.0 \pm 10.0$ & $62.8 \pm 9.3$ & $70.3 \pm 9.7$ & $77.0 \pm 8.7$ & \\
\hline$\sum$ Skinfolds $(\mathrm{mm})$ & $36.9 \pm 17.0$ & $38.9 \pm 15.3$ & $42.7 \pm 17.0$ & $35.4 \pm 11.7$ & $37.9 \pm 13.0$ & $40.9 \pm 13.8$ & \\
\hline Vertical Jump (cm) & $39.4 \pm 5.3$ & $41.8 \pm 4.3$ & $43.8 \pm 5.2$ & $38.8 \pm 4.6$ & $41.1 \pm 4.7$ & $43.1 \pm 5.2$ & \\
\hline Medicine Ball Throw (m) & $5.4 \pm 0.5$ & $6.0 \pm 0.5$ & $6.5 \pm 0.5$ & $5.4 \pm 0.6$ & $5.9 \pm 4.7$ & $6.5 \pm 0.6$ & \\
\hline $10 \mathrm{~m}$ Sprint $(\mathrm{s})$ & $1.95 \pm 0.08$ & $1.91 \pm 0.08$ & $1.88 \pm 0.08$ & $1.96 \pm 0.08$ & $1.91 \pm 0.09$ & $1.87 \pm 0.08$ & \\
\hline $20 \mathrm{~m}$ Sprint (s) & $3.34 \pm 0.14$ & $3.25 \pm 0.13$ & $3.19 \pm 0.12$ & $3.36 \pm 0.16$ & $3.26 \pm 0.16$ & $3.18 \pm 0.13$ & \\
\hline 30m Sprint (s) & $4.67 \pm 0.22$ & $4.51 \pm 0.19$ & $4.40 \pm 0.17$ & $4.70 \pm 0.24$ & $4.55 \pm 0.22$ & $4.42 \pm 0.20$ & \\
\hline 60m Sprint (s) & $8.67 \pm 0.50$ & $8.34 \pm 0.38$ & $8.07 \pm 0.37$ & $8.83 \pm 0.54$ & $8.42 \pm 0.47$ & $8.13 \pm 0.40$ & \\
\hline Agility 505 Left (s) & $2.56 \pm 0.13$ & $2.47 \pm 0.10$ & $2.44 \pm 0.15$ & $2.57 \pm 0.16$ & $2.48 \pm 0.10$ & $2.42 \pm 0.08$ & \\
\hline Agility 505 Right (s) & $2.57 \pm 0.15$ & $2.48 \pm 0.12$ & $2.47 \pm 0.14$ & $2.56 \pm 0.16$ & $2.50 \pm 0.11$ & $2.45 \pm 0.14$ & \\
\hline \multirow[t]{2}{*}{ Estimated $\dot{V} \mathrm{O}_{2 \max }\left(\mathrm{ml} \cdot \mathrm{kg}^{-1} \cdot \mathrm{min}^{-1}\right)$} & $48.6 \pm 4.8$ & $50.6 \pm 5.0$ & $50.6 \pm 4.6$ & $47.6 \pm 5.2$ & $49.8 \pm 3.8$ & $52.2 \pm 3.8$ & \\
\hline & & Quartile 3 (3) & & & Quartile 4 (4) & & \\
\hline Age (years) & $13.29 \pm 0.08$ & $14.29 \pm 0.08$ & $15.29 \pm 0.08$ & $13.07 \pm 0.09$ & $14.07 \pm 0.09$ & $15.07 \pm 0.09$ & \\
\hline Height $(\mathrm{cm})$ & $172.1 \pm 6.6$ & $177.5 \pm 5.5$ & $180.1 \pm 5.1$ & $164.0 \pm 8.3$ & $171.2 \pm 6.0$ & $175.9 \pm 4.7$ & \\
\hline Sitting Height $(\mathrm{cm})$ & $88.1 \pm 4.0$ & $91.0 \pm 3.4$ & $92.4 \pm 3.7$ & $81.4 \pm 5.9$ & $86.8 \pm 4.1$ & $89.5 \pm 4.5$ & \\
\hline Body Mass (kg) & $65.1 \pm 11.5$ & $72.4 \pm 11.1$ & $78.1 \pm 12.8$ & $56.9 \pm 10.1$ & $66.1 \pm 7.9$ & $74.5 \pm 8.7$ & \\
\hline$\sum$ Skinfolds (mm) & $34.2 \pm 12.6$ & $39.4 \pm 15.4$ & $40.4 \pm 14.8$ & $37.6 \pm 15.9$ & $42.5 \pm 14.0$ & $44.7 \pm 20.1$ & \\
\hline Vertical Jump (cm) & $37.4 \pm 4.2$ & $39.8 \pm 3.5$ & $42.6 \pm 3.9$ & $36.8 \pm 4.5$ & $40.3 \pm 5.1$ & $44.2 \pm 4.9$ & \\
\hline Medicine Ball Throw (m) & $5.8 \pm 0.9$ & $6.0 \pm 0.8$ & $6.8 \pm 0.9$ & $5.0 \pm 0.7$ & $5.9 \pm 0.8$ & $6.6 \pm 0.5$ & \\
\hline $10 \mathrm{~m}$ Sprint (s) & $1.99 \pm 0.12$ & $1.91 \pm 0.07$ & $1.88 \pm 0.07$ & $1.93 \pm 0.09$ & $1.87 \pm 0.10$ & $1.81 \pm 0.07$ & \\
\hline 20m Sprint (s) & $3.44 \pm 0.21$ & $3.28 \pm 0.14$ & $3.20 \pm 0.13$ & $3.34 \pm 0.13$ & $3.24 \pm 0.16$ & $3.13 \pm 0.11$ & \\
\hline 30m Sprint (s) & $4.82 \pm 0.29$ & $4.59 \pm 0.19$ & $4.44 \pm 0.20$ & $4.69 \pm 0.20$ & $4.51 \pm 0.23$ & $4.35 \pm 0.20$ & \\
\hline 60m Sprint (s) & $9.12 \pm 0.68$ & $8.55 \pm 0.40$ & $8.13 \pm 0.48$ & $8.85 \pm 0.49$ & $8.50 \pm 0.49$ & $8.06 \pm 0.44$ & \\
\hline Agility 505 Left (s) & $2.61 \pm 0.12$ & $2.51 \pm 0.18$ & $2.45 \pm 0.17$ & $2.58 \pm 0.06$ & $2.48 \pm 0.08$ & $2.43 \pm 0.07$ & \\
\hline Agility 505 Right (s) & $2.62 \pm 0.20$ & $2.53 \pm 0.13$ & $2.50 \pm 0.16$ & $2.58 \pm 0.10$ & $2.44 \pm 0.09$ & $2.45 \pm 0.07$ & \\
\hline Estimated $\dot{V} \mathrm{O}_{2 \max }\left(\mathrm{ml} \cdot \mathrm{kg}^{-1} \cdot \mathrm{min}^{-1}\right)$ & $43.7 \pm 7.6$ & $47.6 \pm 5.5$ & $50.6 \pm 5.6$ & $49.3 \pm 3.3$ & $49.4 \pm 2.3$ & $53.1 \pm 1.8$ & \\
\hline
\end{tabular}

Note: The numbers in parentheses in column headings relate to the numbers used for illustrating significant (p<0.05) differences in the pairwise analysis. 


\section{Figures Captions}

Figure 1: Mean \pm SD for Height over Time (i.e., Annual Age Group) According to Maturation Group.

Figure 2: Mean \pm SD for Med-Ball Throw over Time (i.e., Annual Age Group) According to Maturation Group.

Figure 3: Mean \pm SD for 60m Sprint over Time (i.e., Annual Age Group) According to Maturation Group.

Figure 4: Mean \pm SD for Height over Time (i.e., Annual Age Group) According to Relative Age Quartile.

Figure 5: Mean $\pm \mathrm{SD}$ for Estimated $\dot{V} \mathrm{O}_{2 \max }$ over Time (i.e., Annual Age Group) According to Relative Age Quartile. 
Figure 1: Mean \pm SD for Height over Time (i.e., Annual Age Group) According to Maturation Group.

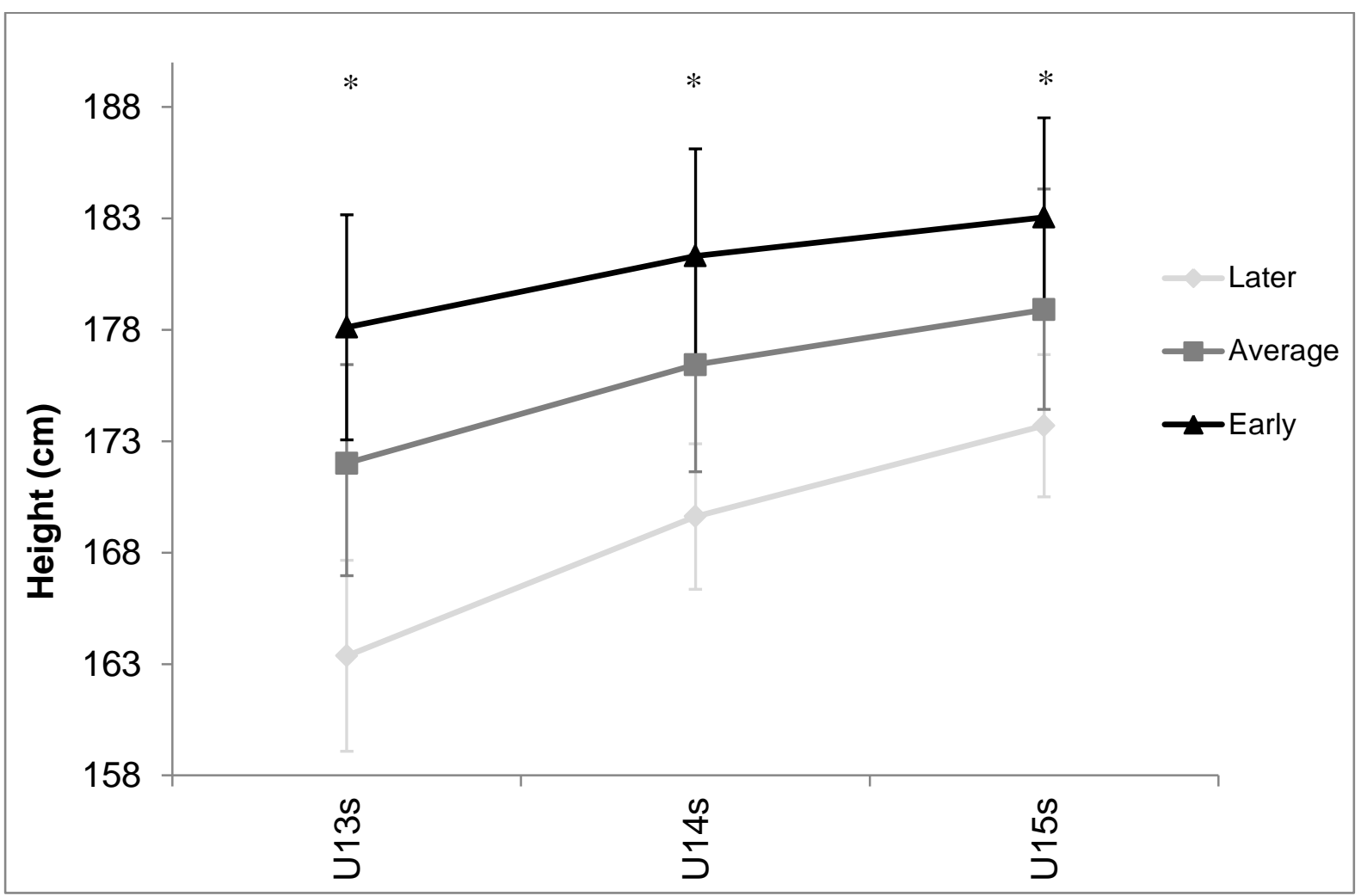

*Significant differences between Early, Average and Later maturing Groups $(p<0.05)$ 
Figure 2: Mean \pm SD for Med Ball Throw over Time (i.e., Annual Age Group)

\section{According to Maturation Group.}

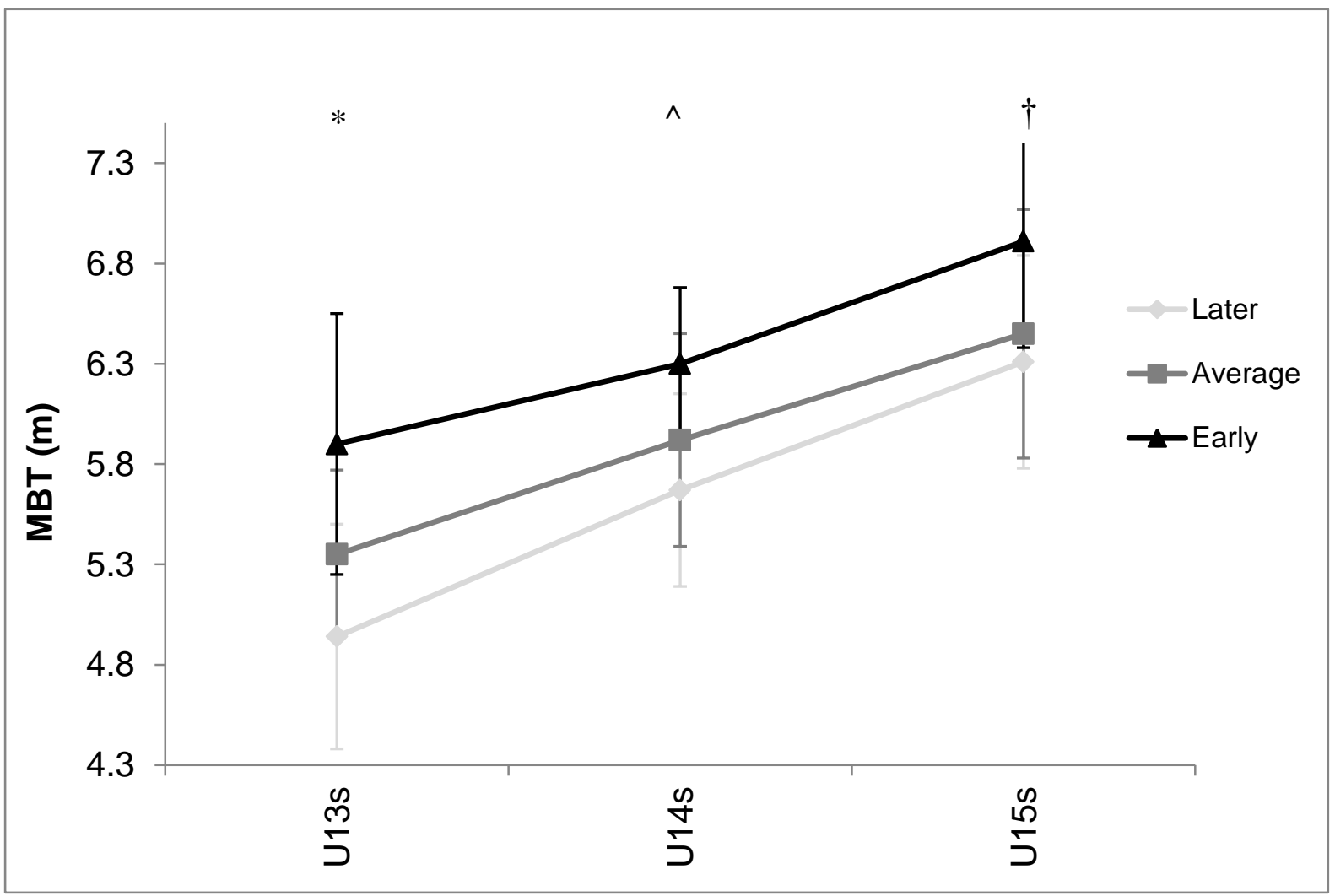

*Significant differences between Early, Average and Later Groups $(p<0.05) ;{ }^{\wedge}$ Early significantly greater than Average and Later Groups $(p<0.05)$; $†$ Early significantly greater than Later Group $(p<0.05)$ 
Figure 3: Mean \pm SD for 60m Sprint over Time (i.e., Annual Age Group) According to Maturation Group.

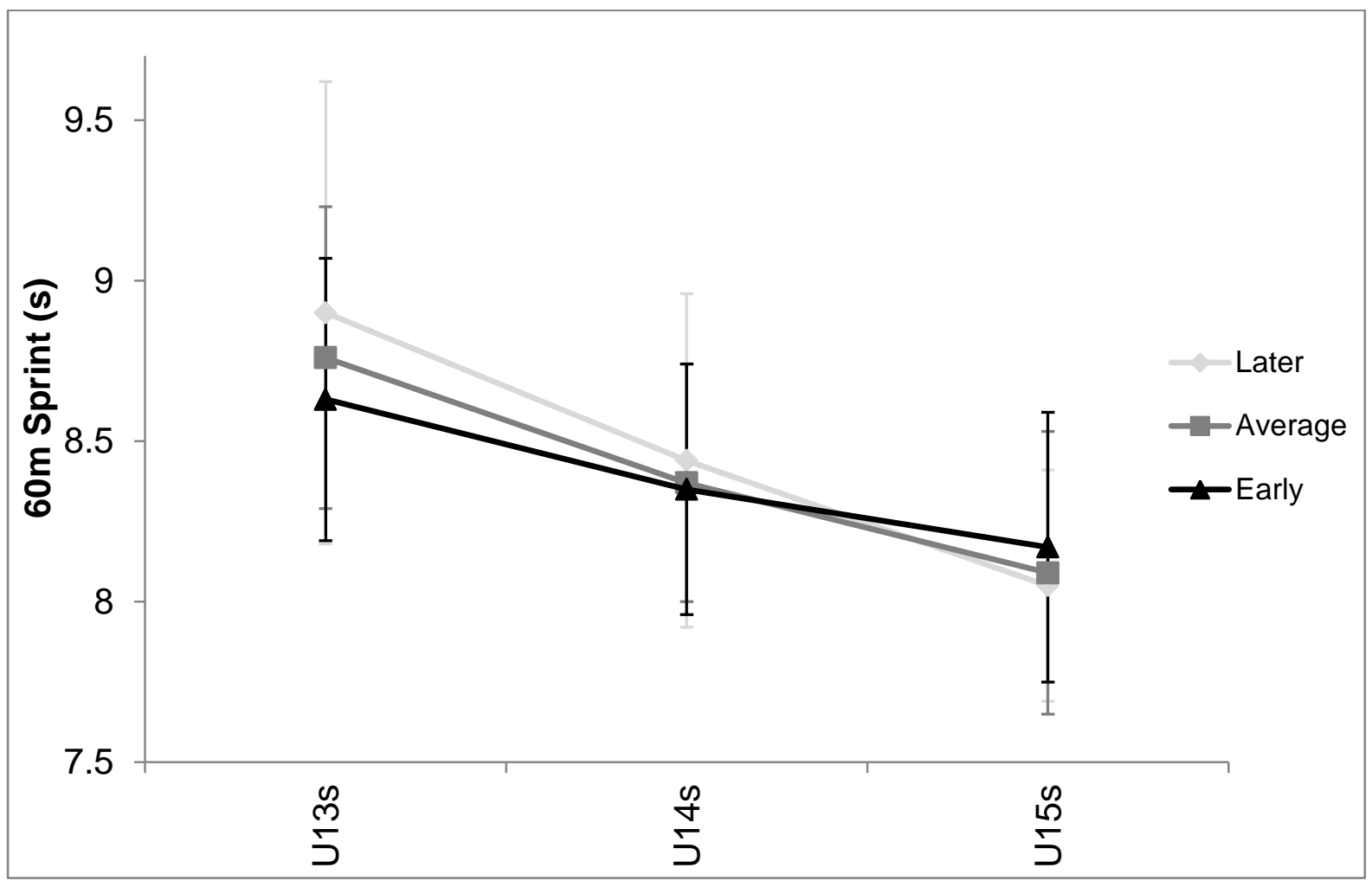


Figure 4: Mean \pm SD for Height over Time (i.e., Annual Age Group) According to Relative Age Quartile

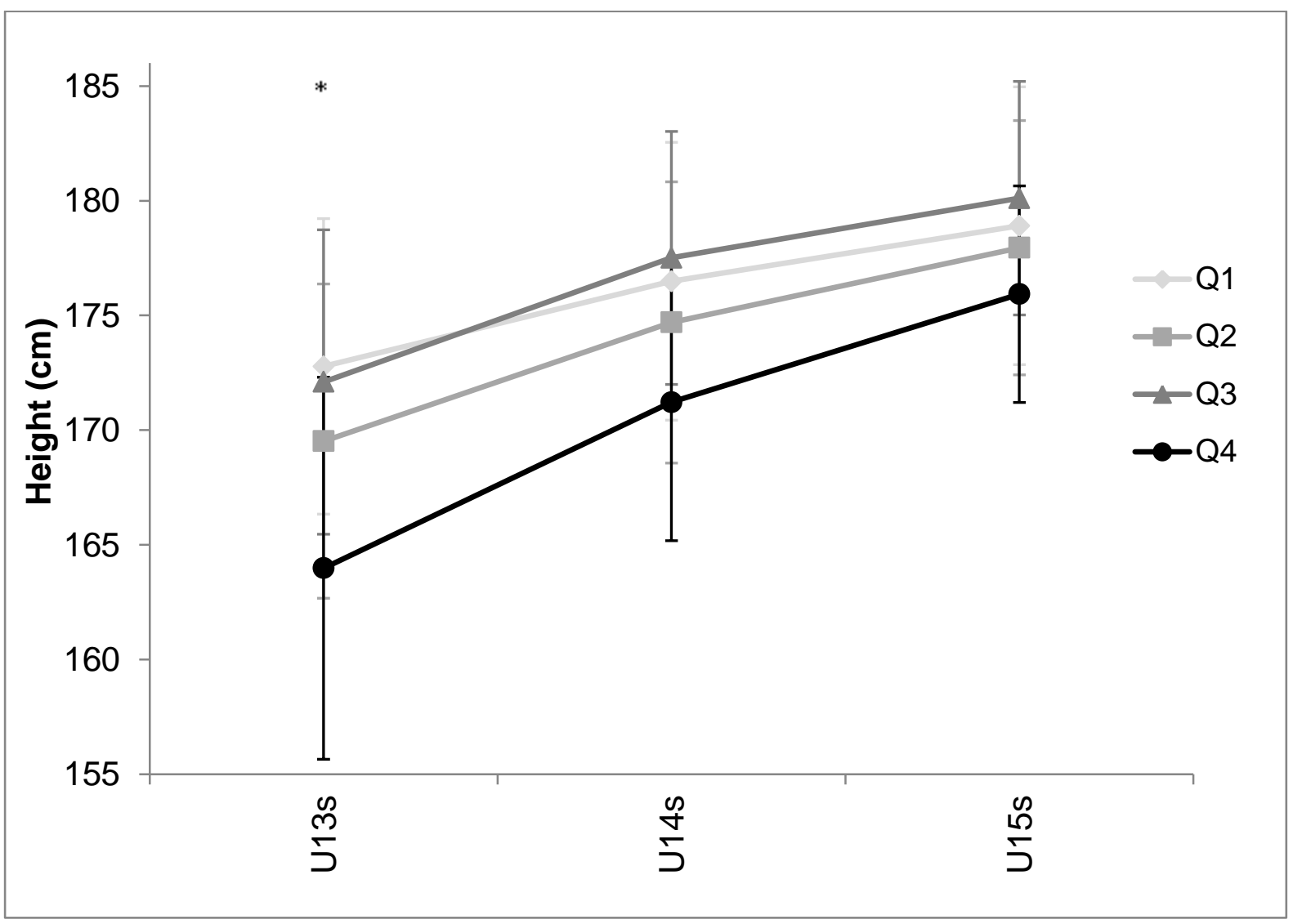

*Q1 significantly greater than $\mathrm{Q} 4(p<0.05)$ 
Figure 5: Mean \pm SD for Estimated $\dot{V} \mathrm{O}_{2 \max }$ over Time (i.e., Annual Age Group) According to Relative Age Quartile.

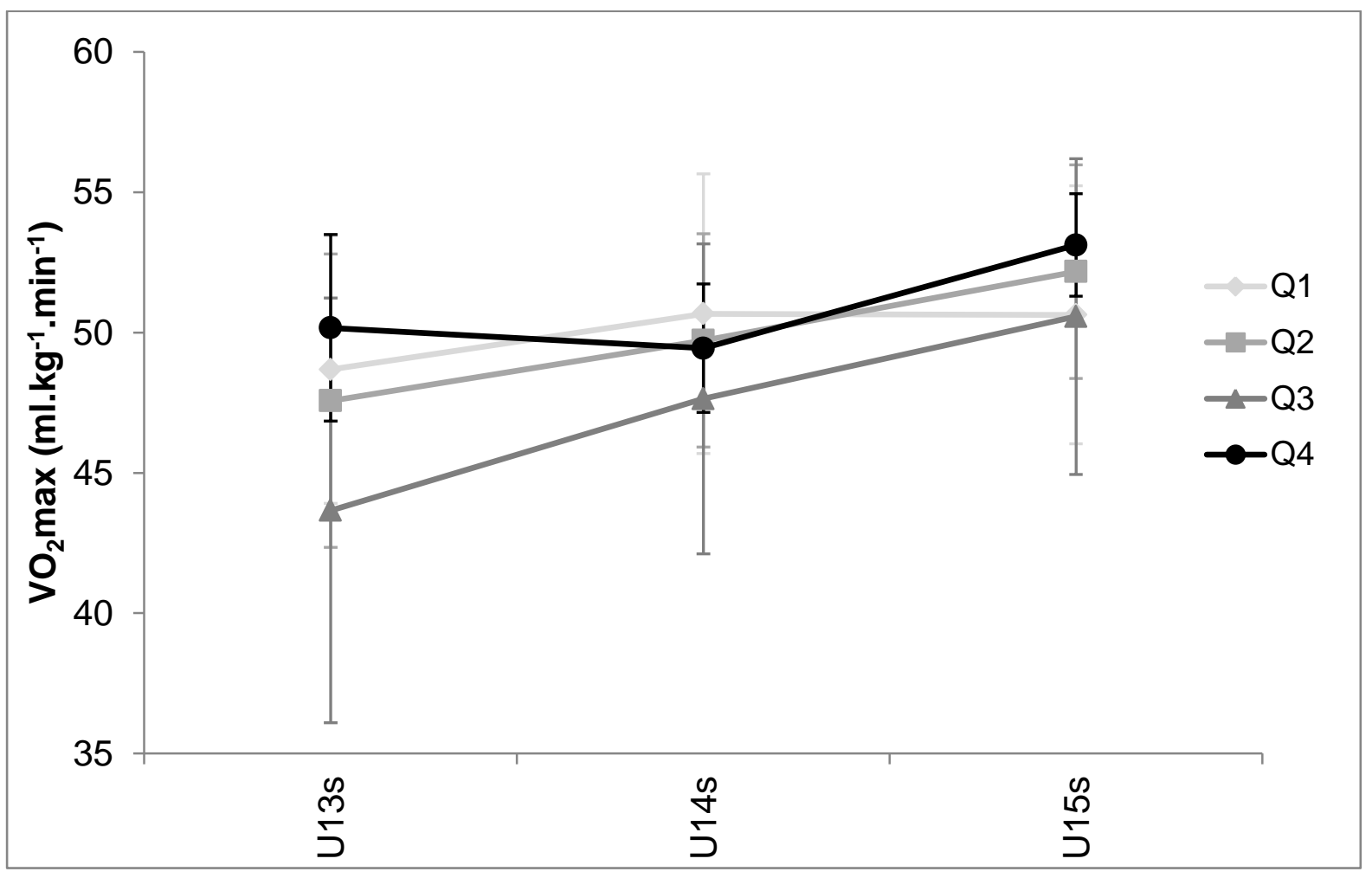

